\title{
Belgeo
}

Revue belge de géographie

$4 \mid 2015$

Miscellaneous

\section{Human Mobility and Accident and Emergency (A\&E) Department: A contribution to the knowledge of invisible flows}

Mobilité humaine et services des urgences: une contribution à la connaissance des flux invisibles

Beatrice Bertazzoni, Giuliano Bertazzoni and Armando Montanari

\section{OpenEdition}

\section{Journals}

Electronic version

URL: http://journals.openedition.org/belgeo/17623

DOI: $10.4000 /$ belgeo.17623

ISSN: 2294-9135

Publisher:

National Committee of Geography of Belgium, Société Royale Belge de Géographie

\section{Electronic reference}

Beatrice Bertazzoni, Giuliano Bertazzoni and Armando Montanari, « Human Mobility and Accident and

Emergency (A\&E) Department: A contribution to the knowledge of invisible flows », Belgeo [Online],

4 | 2015, Online since 30 December 2015, connection on 01 May 2019. URL : http://

journals.openedition.org/belgeo/17623; DOI : 10.4000/belgeo.17623

This text was automatically generated on 1 May 2019.

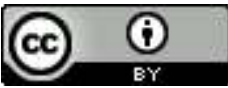

Belgeo est mis à disposition selon les termes de la licence Creative Commons Attribution 4.0 International. 


\title{
Human Mobility and Accident and Emergency (A\&E) Department: A contribution to the knowledge of invisible flows
}

\author{
Mobilité humaine et services des urgences: une contribution à la connaissance \\ des flux invisibles
}

Beatrice Bertazzoni, Giuliano Bertazzoni and Armando Montanari

This research was funded by Sapienza University of Rome, Interdisciplinary Projects 2015 ( $n$. C26M15WHXB)

\section{Introduction}

1 Since the 1980s, Italy has been registering a substantial increase in migration levels due largely to the fact that the political, economic and social conditions of countries of those immigrating do not allow their survival. Immigrants constitute part of the foreign population residing in Italy which, according to the "statistical dossier on Immigration" (Report UNAR 2014), is estimated to be composed of over 5 million of people. The vast majority of these immigrants live in the largest metropolitan areas such as Rome, Milan and Turin, and nearly 700,000 are concentrated in the Lazio region. Only half of the total amount of the immigrant population is in employment and less than one-tenth holds a valid residence permit for either work, family reunion, political asylum, or study reasons. The majority of immigrants come from countries with traditionally high rates of emigration. Even though percentages may vary from region to region, and some communities may be concentrated in certain places more than others, the most numerous non-national populations residing in Italy originate from Romania, Albania, Morocco, China, Ukraine, the Philippines, India, Peru, Bengal, Poland and Tunisia. 
2 This article provides a full report of the results of a study for a project based on the combination of clinical figures with socio-economic data on human mobility within the metropolitan area of Rome. The point of departure of this analysis is the patient register dataset of the Accident and Emergency Department of the Policlinico Umberto I for the period 2000-2013.

3 The hospital registers the greatest number of admissions (approximately 140,000 in 2014) within the Lazio region. It is not only located next to two of the railway stations (Termini and Tiburtina) where many illegal immigrants transit or find shelter, but it is also very close to the Esquilino District, where many (regular and illegal) immigrants work and find home.

4 The clinical observation of the data reveals high occurrences of particular diseases in individuals of specific ethnic origin who have immigrated to Rome. Hence the necessity to gather more information on size and characteristics of migration flows, using a multidisciplinary approach.

5 From many years now, Italy has been a destination country for immigrants. It urges the creation of social policies that will enable the integration of different ethnicities, and the implementation of health monitoring tools together with public health intervention programmes. These programmes should be targeted to address specific health needs that have to be identified. To these ends, the Accident and Emergency unit represents a valid mean of support.

6 The term invisible flow was first used to describe the flow of returnees at the end of colonialism. These return flows concerned individuals coming back to countries of ancient European origins, and were differentiated from the traditional concept of immigration flows (Smith, 2003), as in this case were involved white individuals culturally compatible with the countries of migration. This interpretation of the term was also used for similar phenomena that had taken place during the Second World War (Isaac, 1954). Findlay (1995) addresses the phenomenon of invisible flows referring it to the mobility of skilled personnel migrating for short periods of time, without posing any problem in terms of ethnicity. The author therefore links the concept to the process of internationalization of the production sector, which occurred in the previous two decades. Croucher (2009) instead uses the term invisible flows in the context of new forms of globalization associated with economy and the labour market. More specifically, the scholar focuses on cross-border migration flows (with particular attention to the USMexico border), which follow new types of patterns and have specific characteristics.

7 From a healthcare perspective, the phenomenon of invisible flows, consisting of both informal and illegal immigrants, requires constant use of resources to monitor the health of migrants.

8 Even though, an initial assessment of the health condition of immigrants can be taken in reception centres, it is often difficult to adequately assess their long-term health needs due to the fact that some immigrants either move to other states, or whilst remaining in the receiving country- Italy in this case- very often they do not hold a registered employment contract, or a lease contract, or are not registered on the National Health Service. Practically they are an "invisible human mobility" since complete data of their existence in a specific time and place is not fully documented. The only evidence of their presence in a particular territory is often only found within emergency systems if they happened to have checked in due to a health emergency. 
9 A survey conducted by the ISTAT in 2011/12 assessed through interviews the number of immigrants who had visited an emergency Accident and Emergency Department in the previous three months. There were found to be 66 immigrants out of 1,000 versus 50.5 per 1.000 of Italians.

10 The number of visits to the Accident and Emergency Department is higher for foreigners in the age group 25-34 (77.5 per 1,000), while in the case of Italians it increases after 55 years of age. Indeed Accident and Emergency Departments represent privileged observatories of health issues of a given territory. They cope with the weaknesses of the health system that, in absence of services of prevention and care, imposes the use of health care facilities only in case of emergency.

11 On the basis of this observation, a retrospective observational analysis has been conducted on the data provided by the Accident and Emergency Department of the Policlinico Umberto I of Rome. It is composed of a study on admissions of foreign citizens in the 2000s in the metropolitan area of Rome. The idea is to understand peculiarities and differences between the state of health of the Italians and the immigrant populations. Furthermore, the intention is to assess the variation of health needs over time, as a result of changes in the environmental, socio-economic, and political conditions.

12 The study undertaken aims to improve the medical practice of the personnel working in facilities for immigrants. The knowledge acquired from the study can be in fact useful to quickly detect specific clinical patterns, overcoming any cultural barrier or linguistic obstacle. Moreover, the analysis can provide suggestions to improve health policies, creating, together with the relevant healthcare facilities, pathways for prevention and care of certain diseases beyond the urgency of a critical circumstance that leads the foreign citizen to visit the Department of Emergency Acceptance. Furthermore, replicating this analysis in other urban/metropolitan areas can highlight differences and similarities within the territories of the European Union and represent the basis for a comparison between the EU countries. The results of this study could be used to guide health policies of the EU territories, and to support heath policies of the nations of origin of foreign citizens who often come from emerging or less developed countries.

The data used in this retrospective observational study (all entries to the Accident and Emergency Department of the Policlinico Umberto I of Rome from 2000 to 2013), were extracted from the IT system GIPSE (Information Management ER and DEA). Among the foreign populations identified through the data, it has been conducted an in depth analysis of the nine numerically more representative nationalities. In descending order they are Romanian, Bengali, Peruvian, Chinese, Polish, Albanian, Egyptian, Filipino, and Moroccan citizens.

14 From the statistical analysis of the data collected, emerged groups of diagnosis that differed from the other national groups examined, with respect to two variables: age and diagnostic code ICD-9-CM (International Classification of Diseases $-9^{\text {th }}$ revision - Clinical Modification). There were first identified subgroups of diagnosis constituting at least $50 \%$ of the sample size. It was then chosen to analyse each diagnostic group that, for each national group, differed by at least $10 \%$ from the percentage value of the control population composed of all the other national groups, Italians included. For each national group also examined was the age distribution in every single diagnostic group that accounted for at least $60 \%$ of the sample size of the diagnosis subgroups. 


\section{Methods}

\section{A multidisciplinary approach: advantages and disadvantages}

15 the phenomenon of invisible flows appears to be quite recent. Given the size of the phenomenon, this approach is the only one that can deal with some of the issues that single disciplines cannot solve, as it goes beyond their individual reach. Surveys conducted during International Geography congresses held in 2015 (Eugeo, Budapest, IGU, Moscow) confirmed the interest of many scholars - that have not completed or published their studies yet -in the use of such a multidisciplinary approach. At a methodological level, this study tackles the problem at its roots reviewing literature that has addressed the issue of collaboration between social and medical sciences.

Scientific and technological research is important for the social development of a community; humanistic studies greatly influence the political sphere of a particular territory. The acknowledgement of the existence of a sharp division between the different disciplines created several complications for researchers. The consequence of this division is not only individual in nature, but also creates complex political, environmental, and cultural problems that global society has to face and solve. More than half a century ago, Charles Percy Snow (1959) highlighted the problem of incommunicability between scientists and scholars, shedding a light on their inability to collaborate. According to Snow (1959), to gain a more profound perspective in both the social and the political fields it would be necessary to create a comprehensive approach of the two cultures.

The work of the author has long been subject of discussion, appreciation and also criticism. For this and other reasons, fifty years later, important scientific journals still appraise and discuss his conclusions. Snow (1963) also contemplates the possibility of the emergence of a third culture able to mediate this absolute dichotomy. In fact, the author conceived the idea of a very communicative culture of humanists capable of considering scientific issues.

18 After all, scientists learned how to communicate directly with the general public. Specialised journalists operate at a vertical level, from bottom to top, while professors communicate from top to bottom. In Brockman (1995) the third culture is not a discipline but a process resulting in all pieces released by scientists and other thinkers who engage in scientific divulgation. Through their work and their outreach abilities, these scholars replace traditional intellectuals in making clearer the deeper meaning of our lives. The subject of scientific divulgation has become a crucial element of our society.

Referring to social sciences Kagan (2009) notes that a third culture has grown in importance over the past fifty years. In his work, the author describes prerequisites, vocabulary, and contributions of the natural, social, and humanistic sciences. In particular social and humanistic sciences have the merit of having contributed to our understanding of human nature, and questioned the assumption that biological processes are the main determiners of changes in human behaviour. Kagan (2009) divides sciences on the basis of new parameters that refer to very specific variables such as fund size, funding sources, methods of research management, and ways to gather and use data. The author's message can be summarized in two main ideas: the physical and cultural 
environment matter much more than the genetic structure, and the proper study of human behaviour is based on the analysis of culture and symbols.

For the social sciences, the main sources of information are verbal statements, the observation and measurement of human behaviour, and physiological measurements. The "big science" that has developed in the past fifty years has taken away the excitement of the personal discovery. Large-scale funding necessary for the "big science" have favoured those social sciences in which theoretical innovations are possible with smaller grants.

There is certainly no need to catalogue every last discipline, however it is necessary to recognize the fact that some disciplines have over time transformed more than others, and that some of the definitions that were valid in the years following the Second World War should be reviewed and if necessary revised. A special case is that of geographers, whether physical (natural scientists) or economic (social scientists). They attend the same degree programmes, share the same civic and professional organizations, and internationally belong to the same International Geographical Union (IGU). The IGU in turn adheres to the International Social Science Council (ISSC) and simultaneously to the International Council for Science (ICSU) to which there are also affiliated associations of anthropology and psychology, but not all social sciences. Geography therefore represents at least two cultures and can naturally contribute in overcoming the division between these different disciplines. Expressing itself through spatial definition of phenomena and events, and also with the aid of the latest geographic information systems, this discipline manages to compare and improve communication between different cultures and events through their location on the territory.

The Declaration of Rome (11/21/2014) for Responsible Research and Innovation (RRI) in Europe requires all members of society, civil society included, to be mutually responsible for processes and results of research. This imposes the necessity of collaboration in scientific education, the identification of priorities, management of responsibilities, and transmission of new knowledge to the civil society. In the summer of 2012, the European Commission published a series of measures to make the access to results of publicly funded research easier. These measures are known by the term "open access". This policy will facilitate the access to results to other researchers and companies. Moreover, as stated by Máire Geoghegan-Quinn, the European Commissioner for Research and Innovation, this practice will make more effective the investment of $€ 87$ billion. The necessity of both a multidisciplinary approach and the circulation of the results of scientific research, are now an integral part of all the funding of the European research programme HORIZON 2020, which will be granted between 2014 and 2020.

\section{Human mobility as a key element for understanding social change}

Human mobility has been one of the key themes of interest of the social sciences for a couple of decades now. This particular attention on the subject has followed transformations in the nature of both migration and tourist flows, in the context of advanced globalization, which has affected international trade, capital flows, and economic strategies. The new forms of human mobility have in turn influenced the social and cultural development and have been supported by progresses in information technology, and communication. 

local development. Human mobility is one of the most important ways in which this interrelation is expressed. Places once connected only by flows of the workforce, are now becoming increasingly interrelated by new forms of mobility that result in a significant change in lifestyles, consumption patterns, and political events. These new forms of mobility are also spreading in the context of substantial changes in the more traditional forms of economic migration. Human mobility takes different forms including migration and tourism, this relationship between the two constitutes a further aspect of scientific interest. Tourism is a form of mobility of variable duration, and is interdependent with other forms of migration. It in turn generates more distinct forms of migration such as those triggered by the demand for services, or those more consumerist that can take different shapes depending on duration and reasons, as in the case of seasonal migrations, holiday homes, migrations related to lifestyle changes or retirement. In the decade between 2000-2010, geography has been facing both the problem of re-definition of the concepts of migration and tourism, and the necessity to conduct further research on the synergetic relationship between the two (Hall and Williams, 2002). Several forms of migration generate, in fact, tourist flows, as the immigrant community can become not only the hub of tourist flows, but it can also originate tourist flows of people returning to their own country to visit friends and relatives.

Urry (2000) proposes a sociological manifesto, which examines interdependencies and social consequences of all the different types of mobility of human beings, products, images, information, and waste products. This is the reason why the second part of the title of his book refers to "mobilities" for the twenty-first century. Mobility has to be considered both a geographical and a social phenomenon. Urry argues that social mobility has so far ignored the intersections of social classes, genders, and ethnic groups, with regions, cities, and places. On the basis of this statement the author indicates a new sociological dimension no longer anchored to the concept of human society, but oriented to the search for new paradigms such as networks, mobility and horizontal fluidity. Sheller (2011) historically reflects on the way in which sociology, in the context of the dynamic cultural environment of the 1990s, provoked a debate not only among sociologists, but also among scholars of geography, anthropology, architecture, urban planning, media theory and communication and art.

On the basis of this new multidisciplinary approach, parameters become those of sociology of fluids in which there are no points of starting or arrival; there is no specific perspective of reference, and speed and directions are more important then goals. Therefore come into play characteristics such as viscosity and impermanence, and come into existence walls that obstruct mobility but it should not be ignored the passage by capillary. Fluids' intersections and hierarchical scales of capillary are centres around which authority is organized. In the same way different fluids intersect in "non-places" of modernity. Since 2000, the International Geographical Union (IGU) has established a Commission on "Global Change and Human Mobility (GLOBILITY) in order to explore the methodological premises of the evolution of population flows (Montanari, 2002). Researchers and professors of more than one hundred research institutes (50\% European, the rest from all over the world) have joined GLOBILITY. Recent decades allowed researchers to benefit from the experience and the development of social sciences, and contributions not only come from developed countries of the northern hemisphere, but also from Africa and the Pacific. In order not to have a distorted vision of human 
mobility, attention is in fact being paid to have on board authors that can represent the views of both developed and developing countries. Even though the network has set up as part of the IGU, other researchers from other social disciplines have been invited to actively participate in GLOBILITY (Montanari and Staniscia, 2016).

\section{Results and Discussion}

Admissions to the Accident and Emergency Department of the Policlinico Umberto I from the 2000s to June 2014 were 1,908,240 in total. Check-ins of Italian citizens were 1,651,621; those of foreigners were 256,619. The trend of admissions to the Accident and Emergency Department has over time showed a steady and progressive increase for all national groups examined. A slight aberration can be observed only for the Polish population from 2005 to 2006 (Figure 1).

Figure 1. Distribution of admissions to Accident and Emergency Departments, per country (2000-2013).

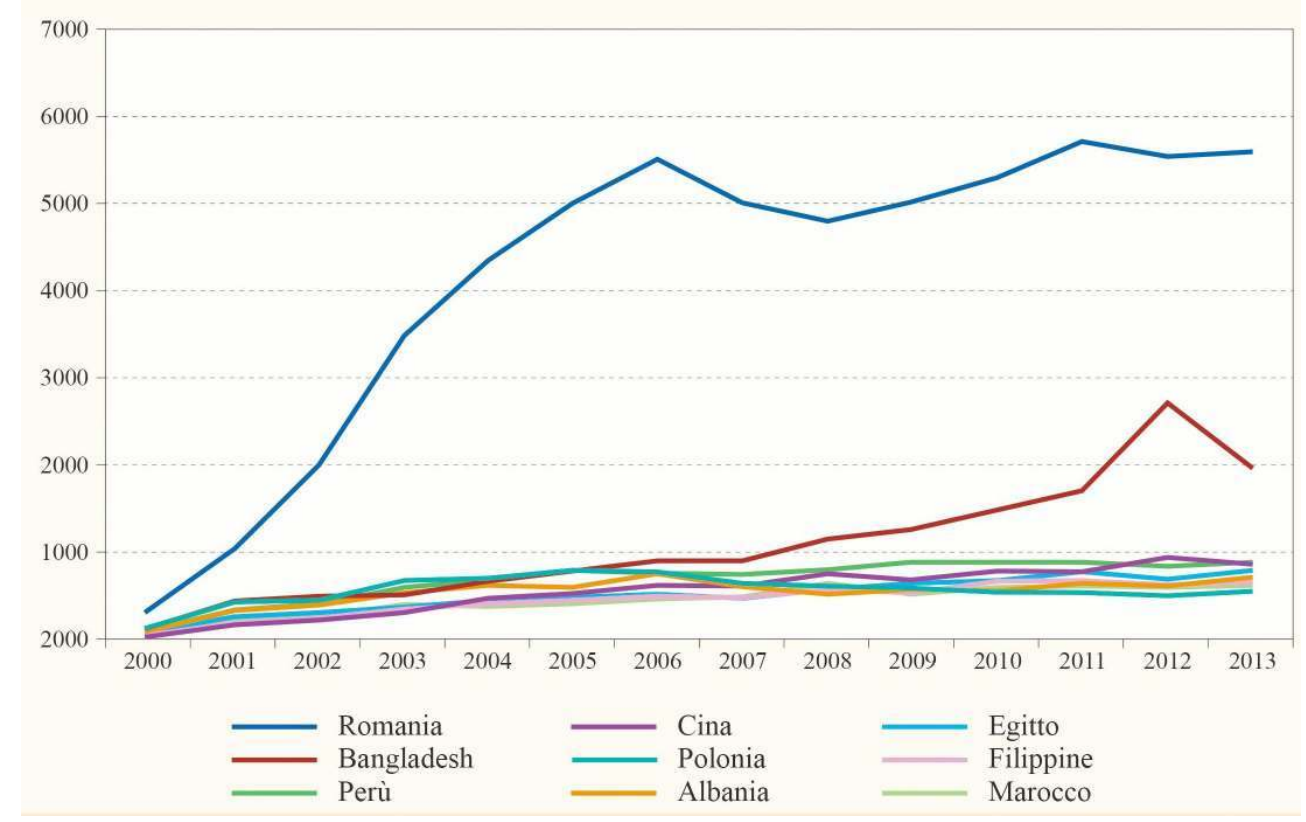

SOURCE: AUTHORS' OWN ELABORATION

On the basis of admissions to the Accident and Emergency Department for the nine ethnic groups identified, it was taken into account the number of residents registered at the Registry Office of the municipality of Rome the $1^{\text {st }}$ of January of each year. The comparable data are those between 2004 and 2013. Statistics for 2012 refer to the national census; therefore the number of registered foreigners may in some cases have not been correctly inserted in the database of the Registry Office. Over the period under consideration, the number of registered foreigners has slightly increased in the case of Egyptian citizens, it has grown by one half in the case of Polish citizens, three times for the Chinese, more than four times for Romanians, and nearly six times for Bengalis.

It appears to be also relevant to consider the coefficient of the number of hospitalizations per thousand of foreign citizens registered at the Registry Office. This coefficient can be examined either as evolving over time or can be compared year by year. If compared to 
the registered population, patients hospitalized over the 2004-2013 period mainly remain constant (Figure 2), or slightly increase in number (as in the case of Bengalis, Peruvians, Filipinos and Moroccans), but have also declined by half (Chinese and Poles) and a third (Romanians and Albanians).

Figure 2. Distribution of admissions to Accident and Emergency Departments, per 1,000 residents (2004-2013).

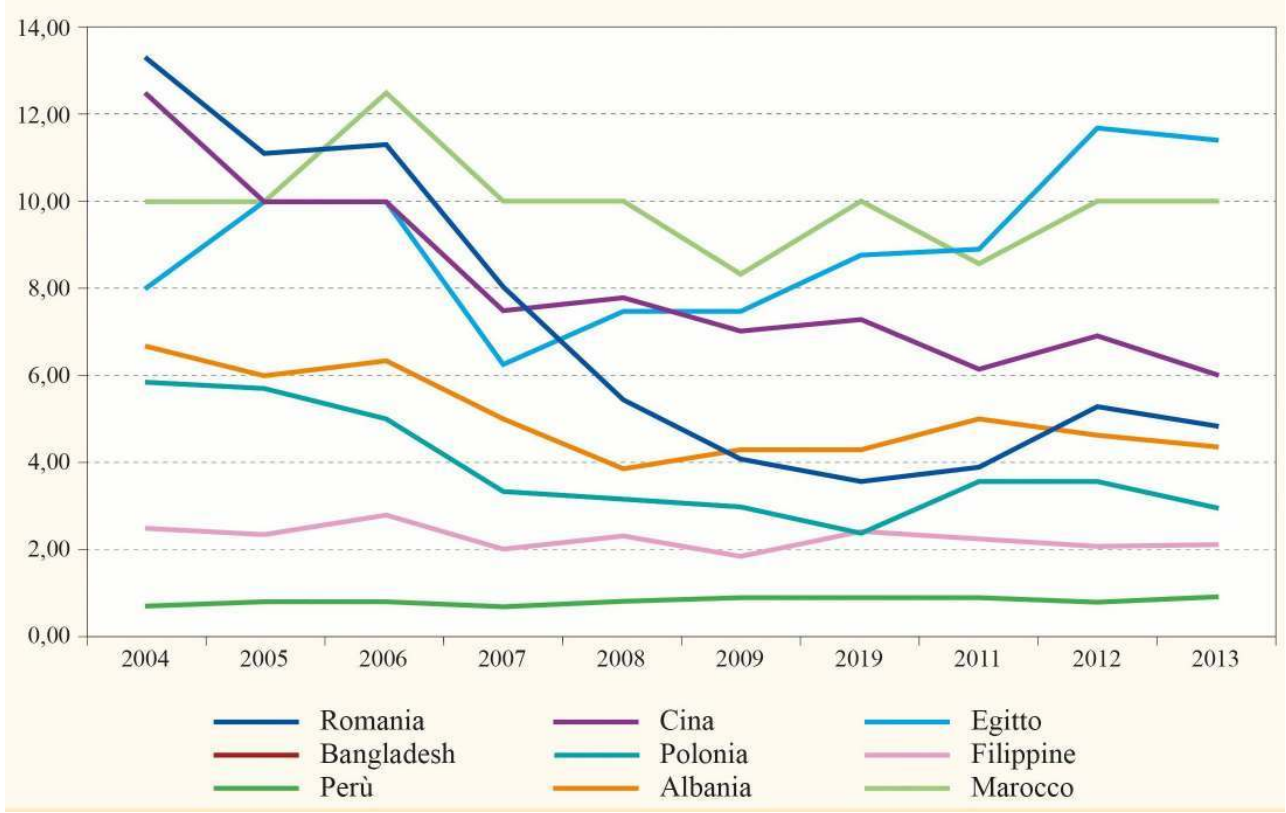

SOURCE: AUTHORS' OWN ELABORATION, BASED ON ISTAT VARIOUS YEARS

The analysis of the different reasons for admissions to the Accident and Emergency Department and the comparison between check-ins of the nine ethnicities examined and the Italian population, reveal the existence of specific diseases for each national group.

Cardiovascular diseases are more frequent in the Italian population of a higher average age than the immigrant community. The frequency of acute coronary syndromes appears to be less in immigrant patients, but the average age of occurrence is in this case significantly lower, especially for certain South-East Asian populations (confirming the data of the literature). Dodani et al. (2012) assume the cause to be genetic, however Jayasinghe and Jayasinghe (2009), McQueen (2008), Rahman and Zaman (2008), identify in the risk factors acquired by these migrant populations, the reason of the accelerated atherogenesis, responsible for early cardiovascular diseases. Cases of changes in blood pressure and heart failures are reported in South Americans. Even in this case, the peculiarity is represented by the young age of those affected. Miranda et al. (2013), El Khamlichi et al. (2001), Schneck and Biller (2005) also report the presence of diseases involving heart failure and acute cardiovascular events in the African countries of the Mediterranean basin, as confirmed by the results of this study.

Respiratory diseases are more frequent in the foreign groups. Acute respiratory infection is the disease most contracted, but it has not been found to represent any particular statistical significance against a specific ethnicity.

Polish people register a great percentage rate in the case of gastrointestinal diseases (principally gastro-duodenitis, chronic hepatitis and cirrhosis). Recent publications of the 
Department of Epidemiology of the National Institute of Public Health- National Institute of Hygiene of Warsaw document ineffective programmes of primary and secondary preventions for $\mathrm{HBV}$ and $\mathrm{HCV}$.

Both Polish and Filipino citizens show a proclivity to contract diseases affecting the skin, and as far as the Filipinos are concerned, females contract a higher percentage of urinary infections ( $64 \%$ of those admitted to the Accident and Emergency Department are female Filipinos).

Admissions for tumours (particularly those affecting the female genitalia), and neoplasms of the blood and of the hematopoietic system specifically concern the Romanian population. This seems to be due to the lack of cancer screening tests (e.g. HPV tests) nationwide, as highlighted by Tornesello et al. (2011), Apostol et al. (2010), Arbyn et al. (2009 and 2007) in their studies.

In diseases affecting females, the number of admissions due to pregnancy, childbirth, and postpartum complications, appears higher in all foreign national groups and particularly for younger women compared to the Italian group.

This remark particularly concerns the Romanian population, but also South-East Asians (especially Chinese and Bengali) and Albanians.

Considering the additional classification of factors influencing health status, and the use of the health system for supporting examinations (e.g. for poorly defined symptoms that do not fit in codified diagnosis; examinations and tests to assess age through bone X-ray), percentage values for these diagnostic groups appear to be higher in patients of foreign nationality. This is particularly true in the case of Bengali and Egyptian citizens as those values are four times above average. This figure may be due to the impossibility for foreign nationals to access those services, which are not provided by the system of emergency/urgency, and to the necessity of getting tests in other institutions (e.g. bone age).

\section{Conclusions}

The data analysis highlighted differences between nationalities for some diagnostic groups. It emphasized the relationship between those groups and certain ethnicities (the Romanian population and neoplastic diseases, the Bengali people and coronary heart disease at an early age, Peruvians and diseases of the circulatory system, the Polish population and gastro-intestinal diseases, Albanians and mental and dermatological disorders, Filipinos and genitourinary diseases especially for females, and the Moroccan population and vascular diseases). Identifying genetic ethnicity-related factors and individual risk components, both as alleged causes of diseases and therefore reasons of admissions to Accident and Emergency Departments, the analysis of the literature confirmed the findings of this study. Results of this analysis are particularly important in enhancing greater understanding of how diagnose particular diseases earlier, which is very useful when the patient's medical history is shielded by linguistic and cultural barriers. After the initial care provided in Accident and Emergency Departments, it would be desirable to be able to include these patients in prevention and care programmes.

Some pathologies and some admissions to Accident and Emergency Departments seem to refer to problems of another level. One of the findings emerged from this study consistent across all populations examined is the presence in the territory of a foreign female 
population facing pregnancy at a very early age (if compared to the pregnancy age of Italians). Over the years, the foreign female population has increased, perhaps for family reunion reasons. Such a path primarily requires hospital assistance for medico-legal and economic reasons. It would be desirable to be able to create sexual education programmes and give gynaecological assistance to foreign women beyond the immediate care provided in Accident and Emergency Departments.

41 A final observation should be made on improper admissions of foreign citizens to the Accident and Emergency Department (AED). This phenomenon is often linked to medicolegal problems that make the general medical assistance and the outpatient care inaccessible for foreign citizens without a residence permit. It would be very useful to create information points in AEDs on regulations governing the access to healthcare and treatments of immigrants.

The research results are particularly encouraging in terms of the possibility of establishing a collaboration between medical and social sciences to better understand and plan ahead a situation that has become alarming for scale and consequences. Over the past year, in fact, the phenomenon of invisible flows has been impacting social, economic, and political life of the EU citizens. Hence the necessity of further investigating these issues. Moving from an analysis carried out on a transit node, the research team has therefore decided to conduct a structured study on how irregular forms of human mobility move in networks and transfer their problems on multiple nodes on both the Italian and European territory.

\section{BIBLIOGRAPHY}

APOSTOL I. et al. (2010), “Cervical cancer assessment in Romania under EUROCHIP-2”, Tumori, 96, 4, pp. 545-52.

ARBYN M. et al. (2007), "The Burden of Cervical Cancer in South-East Europe at the Beginning of the $21^{\text {st }}$ Century", Coll. Antropol, 31, pp. 7-10.

ARBYN M. et al. (2009), "Trends of cervical cancer mortality in the member states of the European Union", Eur J Cancer, 45, 15, pp. 2640-2648.

CROUCHER S. (2009), The other side of the fence. American migrants in Mexico, University of Texas Press, Austin.

DODANI S. et al. (2012), “A po lipoprotein A1 gene polymorphisms predict cardio-metabolic risk in South Asian immigrants”, Disease Markers, 32, 1, pp. 9-19.

EL KHAMLICHI A. et al. (2001), "Pattern of cerebral aneurysms in Morocco: review of the concept of their rarity in developing countries: report of 200 cases”, Neurosurgery, 49, 5, pp. 1015-1021.

FINDLAY A.M. (1995), “Skilled transients: the invisible phenomenon?”, in COHERN R. (ed.), Cambridge University Press, Cambridge, pp. 512-522.

HALL C.M., WILLIAMS A.M. (2002), Tourism and Migration. New Relationship between Production and Consumption, Dordrecht, Kluwer. 
ISAAC J. (1954), British Post - War migration, Occasional Paper XVII, Cambridge University Press, Cambridge.

ISTAT (National Institute of Statistics) (2011-2012), Cittadini stranieri, condizioni di salute, fattori di rischio, ricorso alle cure e accessibilità dei servizi sanitari, http://www.istat.it/it/files/2014/01/salutestranieri_2011-2012-FINALE.pdf?title=Salute+degli+stranieri++-+30\%2Fgen\%2F2014+-+Testo +integrale.pdf.

JAYASINGHE S.R., JAYASINGHE S.H. (2009), “Variant metabolic risk factor profile leading premature coronary disease: time to define the syndrome of accelerated atheros coronary metabolic syndrome in Asian Indians", Singapore Med J, 50, 10, pp. 949-955.

KAGAN J. (2009), The Three Cultures, Natural Sciences, Social Sciences, and the Humanities in the $21^{\text {st }}$ Century, Cambridge University Press, New York.

MCQUEEN M.J. et al. (2008), "Lipids, lipoproteins and apolipoproteins as a risk markers of myocardial infarction in 52 countries (the INTERHEART study): case-control study", Lancet, 372, 9634, pp. 224-233.

MIRANDA J.J. et al. (2013) “Major cardiovascular risk factors in Latin America: a comparison with the United States. The Latin American Consortium of Studies in Obesity (LASO)", PLoS One, 8, 1, e54056.

MONTANARI A. (ed.) (2002), Human Mobility in a Borderless World?, S.G.I. Home of Geography, Rome.

MONTANARI A., STANISCIA B. (2016), "Human Mobility: an issue of multidisciplinary research", in DOMINGUEZ-MUJICA J. (ed.), Global change and human mobility, Springer, Berlin (in print.)

RAHMAN M.A., ZAMAN M.M. (2008), "Smoking and smokeless tobacco consumption: possible risk factors for coronary heart disease among young patients attending a tertiary care cardiac hospital in Bangladesh", Public Health, 122, 12, pp. 1331-1338.

SCHNECK M.D., BILLER J. (2005), “Hemorrhagic Stroke in the Tropics”, Disclosures Semin Neurol, 25, 3, pp. 300-306.

SHELLER M. (2011), “Mobility”, Sociopedia.isa, pp.1-12.

SMITH A.L. (2003), “An introduction”, in SMITH A.L., Europe's invisible migrants, Amsterdam University Press, Amsterdam, pp. 9-31.

SNOW C.P. (1959), The two cultures, Cambridge, England, Cambridge University Press.

SNOW C.P. (1963), The two cultures: and a second look, New York, The New American Library. TORNESELLO M.L. et al. (2011), "High prevalence of human papillomavirus infection in Eastern European and West African women immigrants in South Italy”, APMIS, 119, 10, pp. 701-709.

UNAR (2014), Dossier Statistico Immigrazione, Centro Studi e Ricerche IDOS, Roma.

URRY J. (2000), Sociology beyond societies: mobilities for the Twenty-First Century, Routledge, London.

WALDROPT-BONAIR L.A., SHERMA FOSTER J., GRAY G., ALONSO S., SALES T. (2013), Invisible migrants: a profile of irregular migration, smuggling of migrants and trafficking in persons in Trinidad and Tobago, Research Report, ACP Observatory on Migration, Brussels. 


\section{ABSTRACTS}

This article provides a full report of the results of a feasibility study for a project based on the combination of clinical figures with socio-economic data on human mobility within the metropolitan area of Rome. Acknowledging that Accident and Emergency (A\&E) Departments represent privileged observatories of health issues of a given territory, the point of departure of this study is the patient register dataset of the A\&E Department of the Policlinico Umberto I for the period 2000-2013. The data analysis reveals the existence of a specific relationship between diagnostic groups and certain ethnicities immigrated to Rome. Through a multidisciplinary approach, the analysis undertaken aims to improve the medical practice of the personnel working in facilities for immigrants. The knowledge acquired from the study can be in fact useful to quickly detect specific clinical patterns, overcoming any cultural barrier or linguistic obstacle. Moreover, the analysis can provide suggestions to improve health policies, creating, together with the relevant healthcare facilities, pathways for prevention and care of certain diseases.

Cet article présente les résultats d'une étude de faisabilité dans le cadre d'un projet basé sur le croisement des données cliniques avec les données socio-économiques relatives aux mobilités humaines dans l'aire métropolitaine de Rome. Partant du constat que les services des urgences représentent des observatoires privilégiés des problèmes de santé sur un territoire déterminé, cette étude s'appuie sur la base de données des enregistrements des patients au Service des urgences de la Policlinique Umberto I sur la période 2000-2013. L'analyse des données révèle l'existence d'une relation spécifique entre une série de groupes de diagnostics et certaines origines ethniques. Au travers d'une approche multidisciplinaire, l'analyse vise à améliorer les pratiques médicales du personnel travaillant dans les infrastructures pour personnes immigrées. La connaissance acquise grâce à l'étude permet de détecter rapidement des schémas cliniques spécifiques, au-delà de toute barrière culturelle ou obstacle linguistique. En outre, l'étude peut fournir des suggestions visant à améliorer les politiques sanitaires en développant, avec les établissements hospitaliers compétents, des pistes de prévention et de soins dans certaines pathologies.

\section{INDEX}

Mots-clés: mobilité humaine, flux invisibles, immigration, service des urgences, admissions, Policlinique Umberto I, Rome

Keywords: human mobility, invisible mobility, immigration, accident and emergency department, admissions to accident and emergency departments, Policlinico Umberto I, Rome

\section{AUTHORS}

\section{BEATRICE BERTAZZONI}

London School of Economics, beabertazzoni@gmail.com

\section{GIULIANO BERTAZZONI}

Sapienza University of Rome, giuliano.bertazzoni@uniroma1.it 


\section{ARMANDO MONTANARI}

Sapienza University of Rome, armando.montanari@uniroma1.it 